INTERNATIONAL JOURNAL OF

MULTIDISCIPLINARY STUDIES IN ARCHITECTURE

AND CULTURAL HERITAGE

\title{
Policies and Plans for the Development of Traditional Handicrafts and Local Industries in Egypt
}

\author{
Badawi Ismail a, *
}

\begin{abstract}
Traditional handicrafts and local industries face many challenges, which, through their identification, must learn lessons from the obstacles and problems that negatively affect the efforts exerted in the implementation of economic empowerment projects. The following are the following: Limited direct investment in traditional industries. Traditional handicrafts are considered a noneconomic social sector that has been severely affected. Lack of accurate statistical data for traditional and traditional industries and craft projects to enable them to obtain knowledge of the size of the sector, its production capacity, its need for raw materials, qualified manpower, financing and training. Difficulties related to the flexibility of work in these industries, due to the combination of manual and manual activity of seasonality and instability. Weak funding for the traditional and traditional industries sector, with adherence to the commercial register to obtain loans for financing. Lack of reliable information base in both development studies and programs. Poor culture of consumption of traditional product among citizens. The weakness and decline of investments in this sector. Non- classification of investments in regions and regions by level of economic growth.

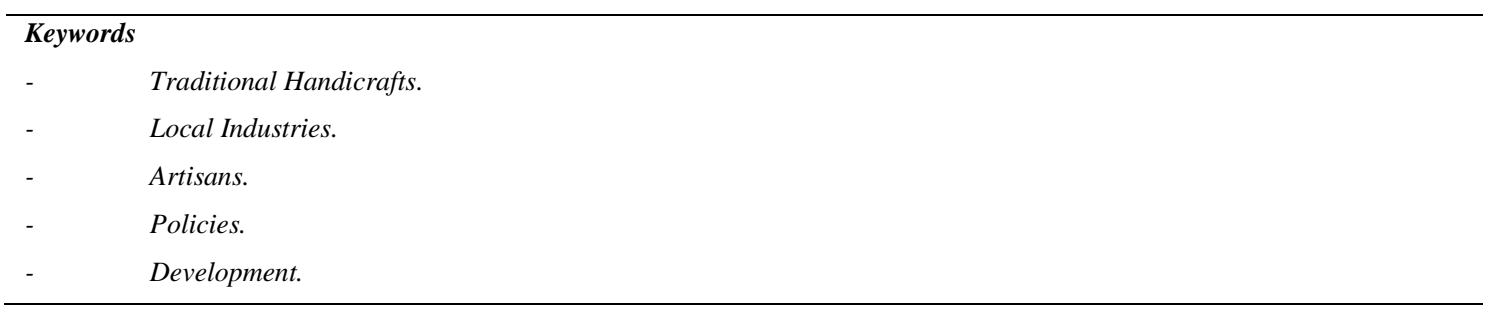

\section{Introduction}

The weakness in the collective systems of production and marketing in line with the importance of the sector. Lack of existing institutions for qualified human resources to compete in economic competitiveness. Competing with products manufactured mechanically or half to traditional products. The low role of conservation of traditional crafts especially endangered. Absence of health awareness and lack of industrial awareness of the minimum health and safety conditions. 
Absence of preventive measures for some trades such as pottery. The negative impact on the environment and air pollution, especially in the areas of the pottery industry.

Absence of social coverage appropriate to the specificities and customs of the traditional industries sector.

Economic and social transformations have led to the dismantling of trades and the factthat artisans have been forced to go to government jobs. The negative impact of the economicand social transformations on the artisan community led to the abandonment of most of them to practice crafts and the deterioration of cultural identity and the loss of a large part of the jobopportunities. Technical view of the literal and linking the concept of character with social and social and lack of possibilities. Lack of opportunities to develop skills and develop social capabilities. Reliance on imports to meet needs that can be produced domestically based on local resources. The reluctance of generations to practice crafts and manual labor in spite of the efforts exerted by governmental and non- governmental bodies to introduce and encouragethe letter. The loss of the handicrafts and handicrafts sector to an honorable body that organizesits activities and sponsors it, thus dispersing efforts. Lack of planning, coordination and follow-up due to the multiplicity of overlapping entities in the sector. The absence of a new generationwhose task is to preserve and develop these trades. The reluctance of the new generation of craftsmen and others to seek jobs that generate higher incomes. The weakness of the possibilities that help artisans to develop their products and reach the consumer, which contributed to the flow of alternative or imitation goods.

Low level of education as most artisans suffer from low level of education. 
Some consider the handicrafts sector as a craft. Is doomed to disappear because artisans who continueto produce in ways that they inherited from their parents and grandparents cannot guarantee their livelihood or marketing their production. Limited activity. Weak financial capabilities. Poor staff training and lack of management development. Lack of standards and controls for import and export of craft products. Difficult to provide raw materials. Poor coordination between the relevant bodies.

The scarcity of support and entrepreneurship for the establishment of small enterprises.Poor qualification of the culture of self- employment. Lack of a vision of self- employment and limited desire for government work. Lack of policies associated with micro and small enterprises. Insufficient market information. The difficulty of marketing and manufacturing because of the intensity of global competition resulting from the cheap production cost. The inability to produce in economic size. Poor management efficiency of owners of small and micro enterprises. Poor efficiency in dealing with competition as a marketing problem. Lack and weakness of the concept of customer service. Lack of innovation and continuous training of designers. Absence of quality standards and lack of quality signs. Many brokers in the fieldof marketing.

Limitation of dealing to develop traditional industries, heritage and craft from a social point of view. The absence of any recovery or development policy, which has lost its economiccharacter and wasted opportunities for development and effective contribution to the efforts ofcomprehensive development. Lack of entrepreneurship and the search for innovation, innovation and market developments. To focus the concept of traditional industry among people as old, sterile and unchangeable. The 
policy of forms and dependence on the state, whichwas bound by the traditional mind of the manufacturer, which reduced the opportunities for initiative and creation and openness to the economic environment in various forms. Not investing and exploiting that society is accurate. It draws its strength from its creative and heritage balance accumulated through ages and generations. Absence of scientific and quantitative studies and accurate indicators. Lack of an organizational framework that definesthe components, limits and qualifications of the sector. Absence of an organizational framework to serve as a base for the implementation of rehabilitation and development programs for the sector. The limited training and training system and the lack of linking it to the concept of innovation and innovation that limit its competitiveness at the national and international level. Limited funding sources and weak interest of the banking sector in the craftand professional industries. The absence of adequate crafts organizations that adopt thedevelopmental dimension of the sector. Shorten interest on large industries without micro. Failure of the concerned agencies to create exhibitions to introduce traditional and heritage products. Lack of privileges for taxes and customs exemptions for raw material. Traditional, traditional and local industries suffer from the problems of lack of training, awareness, development research and the absence of standards and quality of products.

The large gap in information among existing and traditional entities. The industry has developed traditional and traditional industries in stiff and difficult competition with modern industries. Typical of technical education in terms of programs and outputs. Weak organizational structure of traditional and heritage industries. The absence of a raw materials bank and the increase in prices of imported raw materials. Weak labor and capital. The restriction of traditional crafts and 
occupations to some families without others, which means monopoly of the profession in the hands of a limited number and diminishing over time. Lack of interest from the financing agencies in traditional industries and interest in large industries. The small size of local markets for these products and dependence on foreign markets. This type of handicraft industry is not developed in proportion to alternative or imported products or produced through modern workshops and factories at a lower cost. Dissolving the social andcultural fabric of local and rural communities bearing the heritage of traditional and traditionalindustries and crafts. The entry of similar heritage products and competition at low prices led to the recession of many traditional and local industries and some of them fell apart. Weak advertising, advertising and marketing of traditional and local industries, and their appearanceas backward and undesirable. Dispersion and loss of responsibility for supervising the traditional and heritage industries among many institutions. Absence of actual and realistic planning to support and revitalize traditional and heritage industries. The emergence of inherentstereotypes of production. The apparent decline in financial and material support to the traditional and traditional industries has threatened the loss of many traditional industries due to lack of demand, which has been modified only by the collectors of heritage holdings. Lack of production among existing traditional products. Lack of coordination of efforts and supportfor better protection, care and care of artisans. Traditional and traditional industries are low due to a large gap in communication and exchange of information between artisans and stakeholders. Finance is the biggest obstacle to the growth of handicrafts and traditional industries. Limited funding and inability to provide tools and grants to assist in the establishment and development of small projects. Limited foreign funding where it is for a limited period and at the end of funding projects are stopped, 
which causes the frustration of beneficiaries and beneficiaries used on those projects implemented projects. Implementing organizations face difficulties with limited time to achieve economic empowerment. Limited funding for many projects that need more time to achieve economic empowerment that limit access to professional trainers and rely on local trainers. The challenges faced by microenterprises and traditional industries pose a number of challenges to their hoped-for role.

\section{First: Economic Challenges:}

- The decline in demand for its products due to recession and recession due to financial crisesor due to high domestic and foreign competition.

- Deterioration of demand and surplus production capacity.

- The inability to bear losses because of the limited possibilities that may lead to the cessation of activity.

- The inability to cope with the losses caused by the economic downturn due to small size, small capital and production volume.

\section{Second: Investment Challenges:}

- The multiplicity of legislation and the consequent conflict and disruption of business, wherelegislation has changed from facilitation to disability.

- Non- enjoyment of incentives and investment benefits granted to major projects such as customs exemptions - Low prices for loans - Support for energy prices Preference for the purchase of products by the government. 
- Marketing challenges.

- Lack of interest in studying the market to determine the volume of demand for products.

- Lack of competencies, expertise and marketing capabilities of employees.

- Lack of experience with market variables.

- Lack of interest in obtaining technical assistance or guidance from specialized bodies and weak knowledge and experience of the real concept of marketing.

- Lack of interest in obtaining a detailed marketing study for the consumer and the market and determine the expected demand on the products and nature of consumer tastes and preferencesand study of local and imported products in terms of price, quality and quantity.

- Lack or lack of opportunities in contracting or marketing to government agencies.

\section{Third: Management Challenges:}

- Poor management experience of local producers and entrepreneurs

- Lack of technical support in the areas of management, research and accounting

- Lack of financial advantages or opportunities to improve the job status to attract experience to work

- Lack of information on the markets of materials and production requirements Ability to attract management experience to work in micro and small projects 


\section{Fourth: Challenges Related to the Workers:}

- Lack of experience and skills

- The need to ensure the social protection of workers

- Non- observance of the rules of security, safety and occupational health.

\section{Fifth: Technical Challenges:}

- Lack of technical support in the areas of development and acquisition of skills and work elements of the workers of these projects or their owners, which leads to the non- continuity ofthose projects

- Lack of effective and ongoing training programs for training

- The lack of programs to explore the ideas of the pioneers

- Low opportunities in administrative work

- Lack of knowledge of the preparation of feasibility studies

- Lack of awareness of guidance services and guidance for the growth of these projects

- The inability to produce outputs conforming to international standards

- Lack of vital role played by technology incubators and training programs.

\section{Sixth: Financing Challenges:}

- Lack of sufficient funding to meet the needs of the development of projects 
and their exitfrom the circle of traditional production activity to non- traditional activities

- The inability to provide guarantees required to finance small and micro enterprises and theholding of regular accounting books

- The high interest rate required by the financing agencies for loans

- Low ability to market products

- Lack of adequate guarantees to grant financing to small and micro enterprises

- High bank risk for this type of loan

- Lack of insufficient resources to care for local producers and difficulty in accessing training and opportunities that help develop skills and means of income and improve their economic situation.

- Challenges facing the development of traditional crafts in micro- projects such as small capital, low profits, lack of strategy for marketing products and lack of financial support.

- Lack of marketing skills due to low educational level and low marketing opportunities.

- Difficulties in providing project development services and steps to improve the working environment.

- There are no professional associations or organizations at the level to organize this kind of craft.

- There is no real link between the environment and the artisan and his dependence on his mental abilities. 
- The appearance of some products distorted and distorted due to the effects of supply and demand and lack of technical support and design and the lack of reliable reference to the character and heritage.

- The lack of specialized vocational training programs.

- Non- response of traditional products in terms of function and design to consumer needs andlack of efforts by producers to suit products with the requirements of foreign consumers

- Absence of an advertising system for traditional and traditional industries, products andidentity.

- Short channels of distribution of organized and effective production.

- Lack of trademarks for the local product contributing to consumer protection..

- Lack of behavior on the qualifications of important foreign markets.

- The weakness of the exploitation of modern means of communication (Internet) in the revivalof products and definition.

- The absence of a system of information, communication and cooperation led to the reductionof the implementation of development goals.

- The absence of organizational relations between the various activities and activities of traditional industries reduced the positive impact of all activities and efforts of traditional industries.

- Absence of adequate health care system for craftsmen.

- The variety of difficulties that hinder marketing from the internal to the external 
market.

- The lack of an appropriate regulatory framework that is appropriate to economic transfers leads to an impact on the effectiveness of the targeted programs for the traditional and local industries.

- Negligence of lack of attention to human resources led to the emergence of cadres are not eligible for the letter with the low quality and lack of qualified manpower and lack of continuous training guaranteeing the quality and competitiveness of the product.

- Quality of raw materials, raw materials and high prices of imported raw materials. - Increasing inflation rates and their impact on the high demand for the livelihood of the artisanmanufacturer.

- The futility of establishing incubators of traditional characters because of the lack of continuity in projects and lack of experience in marketing.

- The lack of adoption by scientific bodies to study and develop craftsmanship and not to adoptthe stereotyping of the Egyptian heritage so that it can be operated as heritage products.

- Non- adoption of governmental bodies on the development of workshops in terms of development and social development and social security.

- The Ministry of Foreign Affairs and the Egyptian embassies abroad did not adopt the organization of knowledge of heritage products as one of the most important elements of the dissemination of Egyptian culture. 
- The Ministry of Planning and Local Development does not adopt the growth targets of localand heritage characters in each province.

- Lack of familiarity with the mechanics of marketing and how to manage the system of marketing heritage and local products locally, regionally and internationally.

- ignorance of communication mechanisms for craftsmen, bodies and centers capable of designing products that are efficient in communicating with users to meet their demands aesthetic, functional and functional to meet the needs of markets.

- The absence of a supervisor with an academic nature of technical support and the activation of quality mechanisms for the design and production of handicraft products, which loses theircompetitiveness.

- Obstacles to lack of experience in the management of small projects for nondepartmental organizational matters of craftsmanship and lack of familiarity with the quality of operating processes and management methods.

- Low quality of technical education and non- achievement of its objectives of duplication of the interaction between secondary and technical education in Egypt and the preference of families and means of advertising to each other.

- Lack of vocational and technical schools and high student density

- Do not link the curriculum to the existing industries and intended to develop

- Lack of training or practical application in various disciplines in technical 
education, not linked to market developments and needs, traditional teaching methods and lack of interest in traditional crafts and industries and the lack of modern educational means to keep pace with the growth and development of crafts and industries.

- The age of manual mastery has disappeared because of the culture of the new generation ofcomputer proliferation and the speed of communication, which has killed many of the values of these professional crafts that require months in the production and delivery of heritagepieces.

\section{MECHANISMS AND INTERVENTIONS FOR THE}

\section{DEVELOPMENT OFTRADITIONAL HANDICRAFT, AND LOCAL}

\section{INDUSTRIES:}

Traditional, heritage and tourism industries need more interventions to meetdevelopment projects in terms of interventions:

- Developing industries and enhancing their production and creativity

- Transform traditional and heritage industries into small projects to be competitive and technologically innovative and contribute mainly to the national economy and competition at the global level and able and strong

- Use the appropriate competitive exporters and raise the quality of the products using moderntechnologies and advanced production

- Develop strategies for the development and development of traditional and 
traditionalindustries based on encouraging creativity and innovation.

- The transfer and development of science and technology and technology development to contribute to the formation and strengthening of the system of innovation and creativity.

- Launching the technological innovation program to support research and development and providing partial support for research and development expenditures for new technology and development of new products that can be marketed.

- The use of research and development centers and joint projects of cooperation to sponsor andsupport the process of managing heritage content.

- Setting up programs to encourage professional excellence to motivate creativity and continuity.

- Monitor and review traditional and historical products, historical and technical and quality.

- Conversion of famous designers to create designs, designs and models of products and put them in a bank of designs to be at the disposal of local producers.

- Taking advantage of the international experiences of high efficiency in providing new and innovative designs and supporting the advisory and design skills and qualifying them to meet the modern and future needs of traditional industries projects.

- Provide programs based on the development of technical skills in small projects, especially in generating innovation and creating economic value from the 
application of knowledge.

- Introduce modern designs that satisfy the tastes of consumers and raise the economic value of the product and in favor of export.

- The development of heritage crafts and modernizing them in line with the preservation of their heritage assets.

- Provide the necessary guarantees to help artists to enable them to continue their artisticcreativity and transfer their experiences to future generations.

- Increasing projects, programs and encouraging programs to encourage modern generations tocreate new creations.

- To allocate annual prizes for outstanding achievements in the field of handicrafts to honordistinguished artists.

- Encouraging steps to honor craftsmen to ensure continuous innovation and creativity.

- Promote the methods and themes of innovation, design, availability of services and search formarketing opportunities.

- Modernization and renewal of production by employing and developing the innovation component to emerge from the recession to growth and recovery.

- Adopting modern and advanced mechanisms to increase the competitiveness of traditional, heritage, environmental and craft products to protect the traditional product and develop it on a modern basis to increase production and provide modern and sophisticated products to be competitive in the consumer markets. 
- Establish sound bases for the vocabulary of industrial and crafts heritage aimed at maximizingvalue added by creative ideas.

- Develop programs that add distinctive types of craft products with designs related to identityand originality.

- Introduce modern designs that satisfy the tastes of consumers and raise the economic value of the product.

- The development of some raw materials to equip artisans new skills in terms of the use of different raw materials and new methods.

- Setting up programs for the production of craftsmanship quality and aesthetic touches.

- Develop creative and artistic development programs according to the objectives and policiesfor the development of traditional and heritage industries

- Training talented people to work in handicraft industries to develop their intellectual, creativeand artistic abilities as a tool for future cadres.

\section{Enhance the Quality of Traditional and Traditional Products:}

- Programs of interest in quality are mechanisms for the development of the traditional industries sector and its support to enhance its economic, social and cultural status.

- Holding quality workshops that improve the quality of products of traditional and traditionalindustries, and value, preserve and preserve traditional cultural heritage and enhance its competitiveness locally and internationally. 
- Preserving and developing the national product as one of the main objectives of the nationalstrategy for the development of traditional and heritage industries.

- Holding workshops to revive traditional and traditional industries and crafts and enhance thecompetitiveness of traditional and heritage products both internally and externally.

- Registration of quality badges for traditional and national industries, nationally and internationally as signs of ratification and enhancing confidence in Egyptian products.

- Care of quality as one of the mechanisms to enhance its competitiveness and radiation at thenational and international levels.

- The need to enact laws and regulatory measures aimed at maintaining and reaching the levelof quality that is famous for hand products at the global level.

- Organizing workshops aimed at developing awareness of quality work and the role of qualitybadges in development in the production process as an added value and an important factor inmarketing, attracting investment and workshops aiming at educational side to increase the interest of craftsmen to obtain the quality mark to increase the desire to challenge to compete in the commercial market with the highest level of skill. Quality and workmanship

- Establish rooms for traditional and heritage industries to play a regulatory and legal role in order to enhance the quality of national products and raise their competitiveness.

- The need to register collective trademarks for the ratification of traditional and 
heritage industries at the national and international levels.

- The need to establish the conditions of the distinctive marks of traditional and heritage industries and the organization of grants, use and protection.

- Organizing workshops in the field of specifications, research and development and quality badges.

- Organizing workshops aimed at communicating quality and quality methodology in order to preserve the national heritage and value the image of traditional Egyptian products and ensure sustainable and encouraging development of traditional and heritage industries.

- Organizing a cultural awareness campaign with the concept and methodology of quality withthe participation of local producers and actors.

- Organization of production chains and supply of small producers with means of production and diversification of production quality control.

- Establish a system of control for the quality of traditional products and the use of trademarksfor world- class products.

- The need to develop programs based on heritage technology through the application of modern technology with the need to produce and display quality products that evolve and suitably meet the requirements of the consumer and preserve the heritage.

- Develop development programs related to the system of specifications, quality system, qualityof intellectual property protection, research and development, and 
modernize and strengthen the means of production.

- Provide technical support through the development and modernization of production techniques and the use of modern technology without prejudice to the local and national natureof products.

- Maximizing the role of technology in the processes related to the preparation of raw materialsand some stages of production in a way that does not affect the original nature of the productsand ensure the safety and health standards of local producers.

- Establishing and activating small cooperative projects for youth and women workers throughcooperatives and enhancing the ability to create and innovate and to take advantage of the scattered individual potentials and collect them in a large pot through cooperatives for optimalemployment through small projects.

- Expansion of cultural tourism activities by allocating entire villages for artisanal activities carried out in the framework of major tourism projects. The artisanal production, display and sale activities are carried out into live and open museums of heritage and also allow tourists toview artisans while practicing their craft.

- Offering packages of initiatives aimed at developing high- growth projects, in addition to looking to innovate new products, new services and production technologies, finance, capacity development, management, technology and innovation.

- Introduce initiatives packages that create an innovative environment, support export orientedprojects, and provide assistance to promising local projects in terms 
of funding, government support and innovation promotion.

- Holding a series of meetings in various fields related to the activities of traditional and heritage industries in terms of raw materials, export, customs, health services, social protection, finance and loans.

- Holding programs aimed at improving the working conditions of traditional manufacturers and improving their income and creating more job opportunities.

- Holding a series of meetings aimed at exchanging experiences and experiences, and finding solutions and interventions of common problems to contribute to the development of traditionaland heritage industries at the national level.

- Holding a series of partnership agreements and cooperation with chambers of traditional andArab and foreign industries to exchange expertise, experience and rapprochement among traditional manufacturers and revive traditional marketing.

- Organizing training programs concerned with the care of human victory and product qualityand revitalizing the marketing of traditional and heritage products.

- Convening a series of workshops and meetings to propose solutions and possible measures for development in consultation with various local partners from government authorities, localassociations and economic actors.

- Enhancing the role of the traditional industries sector as a main engine for development by valuing the national product, supporting individual industries, revitalizing traditional local products and restructuring traditional and heritage industries. 
- Establish a number of horizontal programs and development programs to diversify the craftsand their needs according to each regional region and identify the weaknesses and strengths toreach high quality and identify the imbalances and take the necessary measures.

- Rehabilitation of villages producing traditional industries and integrating them into tourism programs and visits.

- Taking measures and procedures in various fields related to the sectors of traditional and heritage industries such as quality, marketing, vocational training and completing the trainingof traditional manufacturers.

- Establish programs in the fields of production techniques, design, occupational safety and health and project management.

- Establish programs for the rehabilitation of traditional industries as a productive sector taking a leading position in the national economic fabric to meet the requirements of the age and provide more employment opportunities using modern measures in management, training, processing, financing and marketing.

- Launching the innovative production environment technology development program, whichaims to provide the necessary funds to improve the efficiency of the production lines and the quality of the products and provide financial support for the product marketing technology.

- Taking measures to achieve balanced and sustainable development that will achieve culturaldiversity and economic heritage.

- Take measures to assist rural areas to develop and maintain traditional and 
traditional craft and crafts development.

- provided the opportunity for initiatives aimed at supporting associations and non- governmental organizations in the field of traditional crafts and industries.

- Equitable distribution of places and projects in different regions of Egypt

- Identify one entity concerned with traditional and traditional crafts and crafts under the official umbrella of the state to work effectively and devote itself to serving the traditional and traditional industries sector and is responsible for preparing detailed plans for development andrecovery programs and projects and managing the activities of these industries in coordinationwith artisans and other concerned parties. Related entities in the fields of training, financing, production, quality assurance and control of products and the establishment of a trademark to it through the development of a system of specifications and work on the application.

- Issuing licenses for craftsmen by profession and establishing a professional register for craftsmen.

- Adopting the General Authority for Handicraft, Crafts and Heritage Industries

- Inventory and documentation of all craft industries in Egypt

- The development of economically useful crafts industries.

- Provide guidance and guidance services to local producers.

- Providing training and qualification services for workers in the fields of handicraft andtraditional industries. 
- Provide programs aimed at developing artistic creative capabilities

- Training talented people to work in craft industries to develop their intellectual, creative,artistic and leadership abilities as a future for future cadres.

- Creating internal and external marketing outlets

- Stimulate the marketing motivation of artisans

- Encouraging the private sector to market the products of artisanal and traditional industries

- Preparation of studies for pilot projects in various craft activities

- Prepare and implement policies and programs aimed at promoting innovation and innovation.

- Organizing training and rehabilitation in coordination with the professional sectors and theconcerned authorities.

- Establish regulations, regulations and executive regulations for traditional and traditionalcrafts and industries.

- Caring for the social conditions of craftsmen and providing social coverage for them and theirfamilies.

- Establishing and encouraging cooperative cooperatives for production, marketing,complexes, centers and villages of art and heritage.

- Raising awareness of the role of traditional and heritage industries in national identity andnational economy.

- Encourage cooperation in all its forms in the field of handicrafts and handicrafts 
- Establishing a national center for studies and research of handicrafts, handicrafts, traditionaland heritage, which deals with the tasks of documentation, creativity, innovation, design, product development, quality standards and completion of studies related to traditional crafts.

The establishment of a coordinating council with membership in the main bodies related to the activities and work of traditional and heritage industries aimed at facilitating coordination between the various bodies related to those industries and enabling the State to play its role tosupport this sector and to overcome the problem of placing these industries as an economic sector away from the routine governmental framework through studies The field survey showsthat the Ministry of Commerce and Sana'a are closer to the tasks, objectives and activity of thehandicrafts sector.

- The suggestion that the Coordinating Council includes the Ministries of Tourism, Finance, Trade, Industry, International Cooperation, Social Affairs, Technical Education, Local and Cultural Development, Antiquities, Tourism and Industrial Associations associated with thesesectors.

- Establish an urgent plan based on the incubation by the state of these industries for a specifiedperiod of not less than five years through the measures of central government care by all possible means to remove these industries from their current status and integrate them in the wheel of development and development of the Egyptian economy and provide and develop regulations and regulations, The reasons for organized work and the good conditions of production, quality of products, marketing and programs aimed at achieving self- reliance on the 
development and organization of production, marketing and access to self- reliance to prevent the complete problem of the state that leads to retreat Traditional and heritageindustries.

- The need to establish branches to supervise the sectors of traditional and heritage industries in each province is specialized in support and photography according to the quality of artisanalavailable.

- To stimulate the establishment of professional associations for craftsmen at the level of Egypt, which has branches in all governorates to achieve the active participation of craftsmen through the achievement and development of the handicrafts sector and traditional and heritageindustries in Egypt and Tom as a technical support and oversee the development and development of these industries.

- Establish companies and cooperatives for production and marketing in the regions of Egypt and preferably include craftsmen practicing the same craft men or women to cooperate on jointproduction and marketing.

- Training artisans on the uncle and collective participation and raising awareness thatcompanies or cooperative societies that include craftsmen and craftsmen to cooperate on jointproduction and marketing is the best way to achieve their goals.

- Signing a partnership concerned with the development of traditional and heritage industries aiming at improving the income of traditional manufacturers and professional clusters and strengthening the productive fabric through the supply of raw materials 
- Promotion of modern methods of the product to meet the global and local markets with different targets.

- Providing technical support through the provision of technical expertise, training, professionaltraining, continuous training of traditional manufacturers, support and marketing of traditionalindustry products and product quality control.

- The use of foreign specialists in the design of traditional Egyptian products

- Implement projects for local producers in the framework of sustainable development and community responsibility.

- Providing the development program for small projects depends on providing support in the organization of production, investment promotion, innovation and participation in the social activities of producers and individual manufacturers

- Providing support for the supply of raw materials and raw materials

- Support, assist and rehabilitate training centers in the field of training for local manufacturersand producers.

- Establishing a professional room for the traditional industry with branches in the governoratesrepresenting craftsmen and keeping pace with the economic and social transformations, establishing a special system for social coverage of the working groups of these industries, determining their working conditions and their material capacities and financing projects through helping the state and approving customs duties on imported products and competitionfor traditional and heritage products. 
- To raise a new generation of villages of traditional industry by expanding the idea of commercial museums in the governorates through which tourists and visitors will be informedabout the various stages of production from the financing of raw materials to the product to themarketing of the heritage product.

- Providing support programs to improve performance and competitiveness through technical support for small projects with the state's contribution in financing advanced development experiences, improving production systems and empowering small enterprises to benefit fromthe available support programs.

- Support programs

- Initiate the completion of heritage villages to introduce products and introduce them and facilitate their popularity and encourage manufacturers and manufacturers and training and help them to innovate and creativity.

- Reduction or exemption of the value of customs duties imposed on raw materials and raw materials used in products of traditional industries.

- Implement the consumer protection system and restore confidence in the products and services of traditional industries by ensuring their quality and activating the best control.

- Improving the condition of artisans by establishing a system of social coverage, defining thesocial security system and establishing a system of social coverage that guarantees disability compensation, the deceased's pension, death benefit and health treatment compensation.

- Reviving traditional industries, handicrafts and heritage by showing the aesthetics 
and valuesof traditional crafts and their role in emphasizing the national identity and enriching it throughthe scientific definition of popular folklore, linking crafts with customs and traditions to communities and reusing manual products in daily life.

- Preserve the distinctive nature of the arts, industries and handicrafts.

- Develop awareness of cultural heritage and handicrafts through educational programs for schools and field visits to the sites where these arts are made at their sites to interact with them.

- The efforts to raise local, regional and international attention to the importance of the handicraft sector as an urban and human civilization and to revive it and provide all necessarymeans of support.

- Care for craftsmen and appreciation of their role and status in society to maintain its continuity.

- Advocate for the care of traditional craftsmen and encourage them in search of better living conditions.

- To stimulate the visual, audio and visual media to play an important role in the definition ofheritage and highlight the importance of the issues of development, tourism and economy.

- Supporting and mobilizing efforts to revive the industrial and handicraft heritage representedin the traditional, handicraft, artistic and environmental industries.

- Protecting the products of traditional industries and handicrafts from 
deterioration and theirdevelopment and removal from the museum situation to the contemporary use situation.

- The development and modernization of crafts in line with the preservation of their heritageassets.

- Inventory and documentation of all traditional and heritage industries in Egypt

- Inventory and registration of all traditional craftsmen engaged in these small projects.

- Taking measures and measures for the protection of traditional and traditional national products and the need to keep pace with them and maintain continuity and respond to the requirements of consumer tastes and ensure income of artisans.

- Marking the products of traditional and heritage industries aiming at preserving the diversityof craftsmanship and protecting cultural heritage.

- Rescue endangered and endangered species.

- Conduct an inventory of the character that deserves attention and preservation

- Documentation using the latest technology.

- Setting up programs aimed at protecting traditional and heritage industries from extinction bypreserving the original Egyptian heritage and the root of history and its legacy by generations of civilizations and working on its development.

- Give him the opportunity to initiatives aimed at the revival and development of crafts and handicrafts in Egypt. 
- Prepare programs to implement policies aimed at preserving the heritage of traditional and traditional crafts and industries and encouraging innovation and innovation.

- Sponsorship and support of educational programs to inform citizens of the importance of crafts and their role in national identity.

- Develop support programs for small projects through the application of the cooperative system to save many trades from extinction by using mechanisms to solve problems that threaten to prevent the continuity and resistance to the products of modern industries.

- Develop programs to highlight, preserve and develop the traditional legacies of heritage industries through training, qualification, development, marketing and marketing of products and the care of artisans.

- Establishing programs to preserve the traditional and heritage industries through mechanismsfor conservation. These include organizing the work in the official sector related to the activities of traditional and heritage industries, maintaining the laws related to the fields of heritage industries and developing planning programs in the fields of training, tourism, social protection, production, marketing, scientific research, In order to turn it into an economic activity aimed at increasing the income of national output, providing employment opportunities for youth, supporting social stability, creating new economic dimensions, preserving heritage and educating generations The importance of heritage.

- Supporting handicrafts and traditional industries by seeking to prepare and 
license craft centers in different cities and villages.

- Give the opportunity for craftsmen to participate international, foreign and internal

- Establishment of an observatory for traditional industries in Egypt aimed at introducing the sector ??? Providing data and data that enable policy identification and assessment of its impacton the sector and assist traditional industry projects to improve their competitiveness through reliable information, conducting economic and technical studies on the sector, presenting the vision to potential investors and obtaining funding and technical support from international donor institutions.

- Encouraging the creation of new micro and small projects through facilitating the transfer methods and access to target markets and helping small enterprises to develop and expand theactivity of small enterprises by creating new projects and providing free services and support from the state at the level of production, marketing and finance. Backed up based on productiondevelopment and quality control assistance.

\section{Promoting Employment Opportunities:}

Employment and investment opportunities face many obstacles and difficulties that impede the development of employment opportunities in entrepreneurship in small enterprises and projects of traditional industries and heritage crafts.

\section{Constraints and Difficulties:}


The obstacles and challenges facing the process of development of pioneers and entrepreneurs and the development of entrepreneurship are as follows;

- Cultural and social barriers. - Access to finance

- Lack of knowledge and business skills

- Women face high unemployment rates.

- Women's employment opportunities at all educational levels are limited.

- Lack of supporting structures for entrepreneurship.

- Complex procedures for registration and licensing.

- Difficult access to markets.

- Local constraints that restrict women's testing of the profession or profession, which leads toa decrease in the participation rates of women in the labor force

- Lack of a culture of entrepreneurship among women.

- Lack of confidence in the ability to establish a project.

- Economic obstacles that prevent women from moving in rural areas and reaching distantmarkets

- Lack of adequate financial services to obtain funding.

- Lack of access to finance for projects.

- Lack of financial management, accounting and marketing skills.

- Lack of property that can be used to guarantee loans 
- Lack of awareness of legal procedures affecting the establishment, continuity and growth ofprojects

- Lack of supporting structures to start and develop projects.

- Lack of programs and services targeting economic empowerment.

_Do not meet the main needs related to the areas of leadership and access to finance, trainingand project management

- Lack of knowledge of licensing processes in rural areas.

- Difficulty licensing for projects that work in homes.

- The difficulty of establishing a registered, licensed and home- based project.

- Obstacles to women starting any project from home.

- $\quad$ Lack of skills, knowledge and information to start business and the urgent need fordevelopment support.

\section{Challenges Related to Employment:}

The challenges facing employment opportunities and capacity building in smallenterprises, traditional crafts and traditional industries are as follows:

- Lack of expertise and skills

- Lack of technical assistance in the areas of providing the skills and elements of work projects, which leads to the non- continuity of those projects.

- Lack of effective and ongoing training programs for training. 
- Rapid demographic growth in rural areas, which exceeds the pace of employment growth.

- Lack of programs to explore the ideas of entrepreneurs

- Lack of supporting structures for entrepreneurship

- Low opportunities in administrative work.

- Poor understanding of extension services and guidance for project success and growth.

- Lack of vital role played by technology incubators and training programs

- Weakness of current projects to produce outputs conforming to international standards

- Lack of ability of projects to attract expertise.

- Lack of financial advantages or opportunities to improve the situation to attract experience towork.

- Poor experience for project owners.

- Difficulties in the application of the code work on the sector of traditional industry due to theseasonality of the craft and its instability

- The low participation of women in the labor market represents a burden and high economiccost.

- Low degree of flexibility of the labor market.

- There is a gap between the attempts and development efforts in the fields of education, training and institutional and legislative procedures 
- The small role of women in economic life.

- The issue of unemployment is the basic and chronic problem in the continuing economy andthe continuation of the policy of recession and reduce employment opportunities locally and regionally

- Social conditions and beliefs are considered obstacles to women's participation in the labor market

- The impact of rural social heritage based on the traditional division of roles between womenand men, making the issue of employment for women not as important as men's work.

- The qualitative distinction between men and women is one of the structural problems in the Egyptian labor market

- Wage levels that reduce the incentive for women to participate because they need incentivesto go out to work in order to leave children or send them to nurseries at high cost.

- Lack of availability of information easily and easily enough for women to the needs of the labor market or job opportunities available as well as training programs and types of expertiserequired.

- Difficulty obtaining funding in case of projects.

- Lack of access to markets and lack of sufficient networks.

\section{Negatives:}

- Lack of appreciation for the role of social women in the care of families and children 
- Non- reflection of development efforts exerted on the participation of women in the labormarket.

- The concentration of women in the government sector, which reflects the seriousness of thesituation under the policies of transition to a free economic sector.

- The low return on human investment in both education and health.

- The reluctance of educated women to participate in the labor market.

- The inability of the labor market and the slow absorption of women.

- The gap between the desire of women and their ability and level of education and their actualparticipation in the labor market and the high unemployment rates, which reached four times the rates for men

- The issue of income between participation in the labor market and the policy of physical independence, which causes problems to empower women economically

- High rates of illiteracy in Egypt, especially in the provinces of the tribal and lack of skills tojoin the labor market

- The level of education is insufficient to enable women economically.

- Dropout of education as the social factor is affecting the leakage or nonenrollment, especially in the border provinces because of the lack of schools or lack of proximity to the gatherings

- Low educational level of females in the governorates of Upper Egypt 
- Lack of access to modern technology and training.

- Typical disciplines in education where trade education represents $25 \%$, industrial $5 \%$ and agricultural 3.

- The stereotyping of education reflects a typical societal image of women's work.

- The stereotyping of women in the labor market is weakened.

The Reasons for the Reluctance of Women Themselves to Join The Labor Market Are:

- Community and family obligations for women.

- The reluctance of the private sector to employ women.

- The reluctance of women themselves to work in the private sector.

- Lack of the necessary services that make it easier for women to reconcile the needs of homeand work.

- Poor economic and social return of women to the labor market.

- The weak absorptive capacity of the labor market in general and family culture, whichprefer women to learn the skills of domestic work rather than labor market skills

- Depriving rural women of their full access to the labor market.

- The illiteracy rate of women increased to $40 \%$ compared with men up to $17 \%$.

- Decreased demand for women's services at work, including the lack of regularity in workcompared to men

- The phenomenon of wage discrimination between men and women, which is 
increasing inEgypt

- Community culture plays a big role alongside the economic dimensions in shaping thecurrent situation of women in Egypt

- Rural and urban women lack basic and modern skills that enable them to manage projectswell

- The difficulty of persuading and sensitizing financial institutions about women's ability tomanage projects well

- The need for part- time training initiatives to increase women's skills.

- Difficult access to women to identify these areas and convince them.

- The lack of confidence of rural women themselves, where many women suffer that they donot do anything important and are below the level

- Rural customs and traditions that are not given great importance to what women do andwhich have negative psychological impact on rural women

- The weakness of the information base of women in general and of rural women in particular

- Lack of study of the situation of rural women and the absence of sound data and

- Lack of social security for the poor segments of the society and the difficulty of access to social security

- The absence of any guarantees or legislation to protect women working in the labor market

- Difficulty in obtaining employment due to lack of skills, training and continuing education 
- Difficult access to training and access to income and improving the economic situation

- Lack of organizational capacity in the areas of development, operation and access to finance.

- Lack of confidence in the motives and subordination of civil society organizations where the impact of these organizations' voices in civil and local society on the success of the efforts of these organizations

- The society's misunderstanding of sources of funding, where there is a lack of clarity about the role that these organizations can play in clarifying to societies their motives unrelated to external interests

- The portrayal of the negative media of women with disabilities, as some media materials play a role in increasing negative discrimination regarding women's participation in the economy

- Community ignorance of the economic empowerment of the social groups is the most difficult challenge

- Absence of programs based on the provision of additional employment opportunities in thesectors of traditional industries

- The exploitation of international demand for ancient Egyptian civilization and art

- Absence of programs based on finding and providing additional employment opportunitiesin the handicraft sector

- Women lack innovative ideas for projects, limited to traditional women's fields in the economy, although their competitive advantage is limited 
- The limited infrastructure supporting projects in the labor market, in addition todiscouraging women from entering the labor market

- Rural areas lack funding and households have difficulty accessing credit and savings tools, which leads to rural families' reluctance to innovate and to adopt existing activities

- The increase in the bank interest rate on financing loans due to the stagnation of growth insmall and micro enterprises

- Lack of education, skills and training is hindering the generation of productive workers andalleviating poverty in rural areas

\section{PLANS TO CREATE AND PROMOTE JOBS:}

The mechanisms and plans for creating and promoting employment opportunities in small and micro enterprises, including heritage crafts and local industries, are as follows:

- The need to shift from management to facilitate the management of development and the multiplication of traditional and heritage industries to create jobs.

- Creating sustainable and income- generating jobs for individuals through development programs and projects.

- Helping to reduce the phenomenon of poverty and unemployment through the implementationof community development programs. 
- Enhancing the role of women in society through development projects targeting women, poorgroups and rural areas

- Building the financial, technical and administrative capacities of associations and institutionsand providing financial resources to stimulate the establishment of projects that provide employment opportunities

- Work to reduce the unemployment rate and reduce poverty through mechanisms to stimulateand support small and micro enterprises.

- Support, strengthen and strengthen the role of women as producers of income through economic empowerment

- Contributing to the reduction of unemployment by providing economic support to entrepreneurs, which increases the volume of work and unemployment

- Participating in raising the standard of living for small and underprivileged entrepreneurs

- Enhancing training and employment opportunities and improving the participation of femalesin the labor market

- Providing advisory services to those interested in establishing income- generating projects oropening small projects and institutions through providing market studies and organizing training programs

- Providing employment opportunities and training opportunities for women.

- Develop and develop the skills and capabilities of rural women and enhance their role and status through training and rehabilitation on the establishment of small 
and micro enterprises

- Establish programs to improve skills and improve performance in crafts.

- Assisting associations and institutions to develop their capacity to identify small projectstargeted at beneficiary groups

- Coordinating efforts with institutions working in the fields of productive social work, thuspreventing duplication of funding and establishment of projects

- Provide programs to empower women economically to cope with high unemployment ratesamong women

- Raise awareness of the role of women in entrepreneurship and its importance in creating valueadded and competitive in the economy.

- Activating the spirit of entrepreneurship among women.

- Encourage more women to undertake project activities.

- Encouraging women to move towards self- employment and management of small enterprises through the organization of training courses in management and feasibility studies

- Handicraft industries help to reduce unemployment and benefit from human resources and females who can perform some of the work in their homes and community participation in theproduction process, which gives a source of income, where the personnel are one of the most important elements of production and an area for export. 
INTERNATIONAL JOURNAL OF

MULTIDISCIPLINARY STUDIES IN ARCHITECTURE

AND CULTURAL HERITAGE

\section{References:}

- $\quad$ Adamson, Glenn. The Invention of Craft. $1^{\text {st }}$ ed. London: A \& C Black Publishers, 2012.

- $\quad$ Auther, Elissa. String, Felt, Thread: The Hierarchy of Art and Craft in American Art. $1^{\text {st }}$ ed. Minneapolis:University of Minnesota Press, 2010.

- Bratich, Jack Z., and Heidi M. Brush. "Fabricating Activism: Craft-Work, Popular Culture, Gender." UtopianStudies 22.2 (2011): 233-260. Web. 1 Jan. 2017.

- Broecke, Lara, and Cennino Cennini. Cennino Cennini's II Libro Dell'arte. $1^{\text {st }}$ ed. London: ArchetypePublications, 2015.

- $\quad$ Bryant, Julius, and Susan Weber. John Lockwood Kipling: Art and Crafts in the Punjab and London. 1st ed.

New Haven: Yale University Press, 2017.

- $\quad$ Buszek, Maria Elena. "'Labor Is My Medium": Some Pespective (S) On Contemporary Craft." Archives ofAmerican Art Journal 50.3/4 (2011): 66-75.

- Charny, Daniel. Power of Making: The Importance of Being Skilled. $1^{\text {st }}$ ed. London: Victoria \& AlbertMuseum, 2011.

- Coatts, Margot. Pioneers of Modern Craft. $1^{\text {st }}$ ed. Manchester: Manchester University Press, 1997.

- Cooke Jr., Edward S. "Modern Craft and the American Experience." American Art 21.1 (2007): 2-9.

- Dormer, Peter. "The Language and Practical Philosophy of Craft." The Culture of Craft. Peter Dormer. $1^{\text {st }}$ ed.

Manchester: Manchester University Press, 1997. 219-230.

- Frayling, Christopher. On Craftmanship: Towards A New Bauhaus. $1^{\text {st }}$ ed. London: Oberon Books, 2011.

- Greenhalgh, Paul. "Introduction: Craft in a Changing World." The Persistence of Craft. Paul Greenhalgh. $1^{\text {st }}$ ed. London: A\&C Black, 2002. 1-17.

- $\quad$ Hamilton, Laura. Radical Craft: Alternative Ways of Making. $1^{\text {st }}$ ed. Birmingham: Craftspace, 2016.

- Harrod, Tanya. The Crafts in Britain in the 20Th Century. $1^{\text {st }}$ ed. New Haven: Yale University Press, 1999.

- $\quad$ Pastor, Julia. "The Materiality of Tapestry in the Digital Age." The Journal of Modern Craft 9.3 
INTERNATIONAL JOURNAL OF

MULTIDISCIPLINARY STUDIES IN ARCHITECTURE

AND CULTURAL HERITAGE

(2016): 289-311.

- Portisch, Anna Odland. "The Craft of Skilful Learning: Kazakh Women's Everyday Craft

Practices inWestern Mongolia." Journal of the Royal Anthropological Institute 16 (2010): S62-

S79.

Received: February 15, 2018

Accepted: April 20, 2018 